\title{
Segmentos para una historia del urbanismo virreinal en el estado de Veracruz [México]
}

DOI: $10.20396 /$ labore.v14i0.8663519

Arquitetura, Cidade e Documentação

Comitê Nacional de Documentação do Icomos Brasil

Daniel Rolando Martí Capitanachi

$<$ https://orcid.org/0000-0001-8610-9469>

Universidad Veracruzana/ Xalapa [México]

Fernando Noel Winfield Reyes

$<$ https://orcid.org/0000-0002-5220-6401>

Universidad Veracruzana/ Xalapa [México]

Nairobi Soledad Díaz Ordaz Montañez

$<$ https://orcid.org/0000-0003-2544-8824>

Universidad Veracruzana/ Xalapa [México]

\section{RESUMEN}

Durante el periodo denominado como virreinal que va desde la llegada de los españoles al litoral del territorio que hoy constituye el Estado de Veracruz en 1519 y hasta la Guerra de Independencia en México que inicia en 1810, varios asentamientos son considerados clave para entender la evolución de las ideas del urbanismo que sería implantado en esta región del Nuevo Mundo y, a la larga, el punto de encuentro de culturas, llegada y tránsito de las rutas comerciales del Virreinato de la Nueva España y su metrópoli colonial europea. Al estudiar la evolución que alcanzan varias de estas ciudades durante los siglos XVI, XVII y XVIII, principalmente, resulta evidente la aproximación a varios casos de tipologías urbanas desde el punto de vista del poder político o religioso de las que emanan: a) las ciudades construidas sobre las preexistencias prehispánicas; b) las poblaciones fundadas por las órdenes religiosas mendicantes; c) los enclaves y sistemas de fortificación en el interior por necesidades de defensa, hacia la parte final del periodo colonial. Y, como eje vertebrador de estos desarrollos, la existencia del Camino Real desde el Puerto de Veracruz hasta la Ciudad de México, que, incluso, vía marítima, alcanzaron territorios en Asia y Europa.

PALABRAS CLAVE

Urbanismo. Virreinal. Estructura urbana.

\section{Segiments for a history of viceregal urbanism in Veracrul state [Mexico]}

\begin{abstract}
During the period known as viceregal that goes from the arrival of the Spaniards to the coast of the territory that today constitutes the State of Veracruz in 1519, and until the War of Independence in Mexico that began in 1810, several settlements are considered key to understanding the evolution of the ideas of urbanism that would be implanted in this region of the New World and, in the long run, the meeting point of cultures, arrival and transit of the commercial routes of the Viceroyalty of New Spain and its European colonial metropolis. When studying the evolution reached by several of these cities during the 16th, 17th and 18th centuries, mainly, the approach to various cases of urban typologies from the point of view of either the political or the religious power from which they emanate, is evident: a) cities built on pre-Hispanic preexistence; b) the towns founded by the mendicant religious orders; $c$ ) the enclaves and fortification systems in the interior for defense needs, towards the end of the colonial period. And, as the backbone of these developments, the existence of the Camino Real from the Port of Veracruz to Mexico City, which even, by sea, reached territories in Asia and Europe.
\end{abstract}

KEYWORDS

Urbanism. Viceregal. Urban structure. 


\section{Introducción}

Aproximadamente en el primer cuarto del siglo XVI, poco después de la caída de México-Tenochtitlan un 13 de agosto de 1521, habrá de continuar la conquista para consolidar durante un periodo de casi tres siglos, el Virreinato de la Nueva España y, consecuentemente, se da la fundación de nuevos asentamientos y poblados, en la medida en la que también se van explorando e incorporando nuevos territorios.

Mucho se ha hablado y debatido sobre las dos ideas fundamentales o, si se quiere, vertientes asociadas al proceso de la conquista: una de orden civil que pone su énfasis en ocupar a los indígenas naturales de esas tierras como fuerza de trabajo cuya explotación permitiría acrecentar la riqueza de las arcas reales a través del tributo; y otra de orden espiritual prácticamente opuesta, que consistió en las representaciones religiosas católicas, del tipo mendicante, alejadas de la visión económica del mundo terrenal, que visualizaban la redención de los naturales a través de la evangelización, para intentar integrarlos de manera justa a una nueva sociedad.

La disputa por el poder entre civiles y religiosos se suscitó hasta los últimos años del siglo XVI, y durante ese lapso, fueron los frailes los que se encargaron de fundar y consolidar la gran mayoría de los asentamientos humanos de la Nueva España; así, aun cuando al hablar de urbanismo novohispano generalmente se alude a la fundación de las grandes ciudades en las que se concentraron los españoles, es necesario considerar a un gran número de poblados que se fusionaron con antiguas fundaciones indígenas o que, en otros casos, surgieron acompañando a conventos y monasterios. También, a finales del periodo colonial, merece asimismo atención especial la creación de un enclave basado en los pri4ncipios de la ingeniería militar para propósitos de eventual defensa de las tierras del interior del Camino Real a la Ciudad de México, ejemplificado por el trazado y construcción de la Fortaleza de San Carlos en Perote (Martí, 2008).

En síntesis, los objetivos del presente trabajo son:

1. Enunciar los distintos modelos de urbanización impulsados durante el siglo XVI, XVII, XVIII e inicios del XIX en lo que constituye el actual territorio veracruzano o del Estado de Veracruz.

2. Estudiar las características de las principales ciudades fundadas por los conquistadores españoles a partir del siglo XVI en dicho territorio ubicado al este de México, los poblados de las órdenes mendicantes y los rasgos urbanos que caracterizaron la provincia del Santo Evangelio en México, así como los casos derivados de necesidades de fortificación y defensa en los siglos subsecuentes hasta el final del periodo virreinal en la que sería llamada Intendencia de Veracruz.

3. Determinar la importancia del Camino Real como eje vertebrador de la economía novohispana y la ruta de integración de localidades veracruzanas.

\section{Principios que tuvieron una influencia marcada para el urbanismo novohispano.}

Comenta Nettel $(1989,23)$ que hasta el siglo XVI, las distintas órdenes religiosas y particularmente las mendicantes fueron integradas en un número significativamente menor, a propósito de lograr una mayor unidad de interpretaciones y prácticas que posibilitaran un mayor poder. Respecto a aquellas que tuvieron una influencia mayor en las ideas y el pensamiento español de este tiempo, se reconocen las de los franciscanos, los agustinos y los dominicos (la primera se caracterizó por el excesivo rigor en la interpretación de los principios religiosos y la acendrada pobreza de sus integrantes).

Años antes del proceso de integración del virreinato en la Nueva España, debe advertirse que ya las órdenes mendicantes habían participado en la evangelización de lugares recónditos en el territorio motivo de la reconquista de España y esta experiencia fue el fundamento de que se les encargara la predica de la religión a los habitantes originales de los nuevos territorios de la América que se iban conquistando, y no al clero secular. Nos dice Kubler (1984, 15-16) que:

La evangelización formal de los mendicantes en México empezó con la llegada de doce franciscanos en 1524. Los dominicos le siguieron en 1526 y los agustinos en 1533. El patrón de actividad de los mendicantes fue definido y establecido por los franciscanos.

Con ello, al compartir el que pudiéramos llamar proyecto franciscano, las otras dos órdenes mendicantes suscriben en los hechos las propuestas de Fray Juan de Zumárraga, primer Obispo de México que se caracterizó por proteger a los indios, y había sido un lector entusiasta de una de las obras más importantes 
difundidas en esa época, destacando la Utopía de Tomás Moro (originalmente publicada en 1516), de igual manera que por los planteamientos humanistas de Erasmo de Rotterdam (Martí Capitanachi, 2008).

Sin embargo, vale la pena matizar que este proyecto franciscano era en buena medida una versión bastante distinta de aquello que propugnaba la jerarquía del clero, buscando fundamentalmente estar estrechamente vinculados con la autoridad papal, y plasmar en su práctica cotidiana un modo de vida, si bien no necesariamente basado en la pobreza, si en una moderación que permitiera también ser un ejemplo vivo para la población nativa que querían convencer y evangelizar. Simultáneamente se irían fundando o dando una nueva forma a los poblados o asentamientos, al margen de que su vocación parecía ser más bien la de no quedarse totalmente establecidos en un sitio.

Otra característica importante a mencionar, son las autorizaciones que estos frailes tuvieron, por ejemplo, para administrar los sacramentos, fundar instalaciones religiosas y templos con relativa independencia de sus superiores y, de ser necesario, vigilar y castigar la conducta de aquellos indígenas que fuesen reacios o se distanciaran de las directrices del proyecto de evangelización y progresiva urbanización del territorio, de ahí que "el poder ilimitado de los misioneros llegaba hasta donde su capacidad lo permitía. El trabajo indígena no era necesariamente remunerado y en caso de rebeldía se castigaba con el látigo o la prisión" (Kubler, 1984, 15).

Sin embargo, el apoyo franco que la Corona de España prodigó hacia el llamado clero secular casi al finalizar el siglo XVI, habría de desplazar la importancia de los mendicantes, al tomar la iniciativa para que, a través de estas jerarquías eclesiásticas, se lograra recaudar el impuesto del diezmo, al tiempo que se hacía una repartición de los indígenas establecidos en el territorio, a manera de potenciar económicamente la sostenibilidad del reino. Con esto se da término a una etapa de colonización de la Nueva España.

En lo político, debe destacarse dos visiones que habrían de coexistir en los nuevos territorios, y por consiguiente de manera simultánea: una república de españoles, y otra de indios. Contrario a este fundamento de segregación, las órdenes mendicantes proponían una sola república, donde indios y españoles, actuarían como semejantes, sin esclavitud. Dicha condición no fue irrelevante, ya que influyó de manera determinante en el urbanismo veracruzano en el momento en el que se hace referencia a los asentamientos y después convertidos en ciudades, que fueron fundados por las ordenanzas reales.

De tal manera que físicamente se puede observar cómo se logró diferenciar y separar el espacio urbanizado para los españoles, del indígena. Mientras que, en las fundaciones de las órdenes religiosas, el espacio para los primeros y luego los últimos se fue organizando alrededor de las iglesias, templos y moradas de frailes, formando más bien una, continua totalidad en expansión.

\section{Modelos urbanos novohispanos}

El concepto de circularidad aplicado de manera teórica o aproximadamente práctica para trazar las ciudades había sido una añeja idea en la que, sobre todo a partir del Renacimiento, aspiraba al logro de una sociedad igualitaria, centralizando los usos públicos como manera de subrayar el poder (Winfield Reyes, 2010, 65-70). Puede entonces mencionarse que, para el contexto europeo, distintos han sido los modelos que a lo largo de la evidencia empírica de la historia urbana exhiben una estructura cuadrada o radial inscrita en la figura de un círculo. Y que, resultaron imperfectos, no obstante, la inspiración ideal inherente, cuando estos modelos se llevaron a los hechos constructivos.

Así que en Europa puede observarse la decisiva presencia de una importante o robusta construcción amurallada que, además de prever la seguridad interior, se convertía en una entidad física de limites perfectamente claros. Sin embargo, la idea de una ciudad cuyo crecimiento fuese ilimitado, basada en una red o trama reticular, vendría a ser un rasgo distintivo de la aplicación de dichos modelos, pero en la etapa de la conquista; a excepción, posiblemente, de los puertos por la constante amenaza que se dio por parte de piratas, corsarios y filibusteros (Martí, 2008). A continuación, se describen algunos de los ejemplos más sobresalientes de los modelos novohispanos que fueran utilizados, independientemente de que, quizá todos puedan ser sintetizados en los principios para el crecimiento de las ciudades ortogonales.

a) Ateniéndonos a la historia, puede señalarse que, el caso inicial que marcaría la aplicación de un paradigma en la Nueva España, fue México, que se construyó sobre las ruinas de la urbe azteca de Tenochtitlán. A pesar de varias especulaciones sobre la preexistencia allí de un modelo urbano de ortogonalidad, Kubler (1984) comenta algunas dudas que el conquistador Hernán Cortés tuvo 
respecto a la reconstrucción de la antigua, acaso intentando seguir aquellos trazos de importantes líneas rectas que llegaban desde los cuatro puntos cardinales. Pero puede añadirse que Cortés, asesorado por algunos de los españoles que lo acompañaban, escasamente ilustrados, no consideraron que la nueva capital residiría sobre un lecho lacustre, además de configurar las calles mediante las fachadas de los edificios limítrofes, quizá con la idea de originar frentes de contención en caso de que hubiese alguna insurrección indígena, ante la carencia de un sistema de muralla que funcionara a manera defensiva. De ahí que el producto fuese una ciudad aparentemente cuadrangular, sin murallas, como un antecedente fundacional para la traza de las ciudades del continente americano, que por lo tanto resultan distintas a las que se pueden estudiar en la península ibérica. Por ello, aunque pareciera fortuita en su origen y disposición, en la Ciudad de México puede compararse, tomando a Cuzco en Perú como ejemplo que, aunque esta última se funda después, sí existe una adecuación a la básica razón de la cuadrícula, simétrica en su aplicación.

b) En segunda instancia, el caso segundo puede estudiarse en aquellas ciudades que se fundan con el expreso consentimiento de la Corona Española, en donde la ciudad tenía su fundación mediante una ordenanza que se emitía al respecto. Se dice que el modelo de desarrollo para el territorio en el virreinato de la Nueva España consideró de manera importante que las ciudades donde se asentaran los peninsulares fuesen viables en cuanto a su función económica y es por eso que se requería un control con las autorizaciones emitidas, y que los nuevos sitios estuvieran alejados de la Ciudad de México, tomando en cuenta que se aplicaba a otra escala territorial un esquema que refleja el control del centro hacia las periferias. De ahí que: "El reflejo espacial de centro-periferia expresa fielmente la imagen del poder absoluto. El centro es la imagen definida por relaciones inequívocamente isotópicas” (Méndez Sainz, 1988, 60).

En suma, dichas ciudades tomaron en cuenta los principios clásicos para su ubicación y emplazamiento, la proximidad de las materias primas y otras riquezas naturales explotables, o sencillamente, ambas estrategias de planeamiento. Y para ello, se obligaba una estricta observación de las reglas y los contenidos del marco jurídico que expresaban con mucha claridad separar, espacialmente, a los españoles de los naturales de esas tierras, y ya avanzado el virreinato, cuando se dio una mayor mezcla racial o mestizaje, a estos últimos con relación a otras llamadas "castas".

Resulta de utilidad comentar que las ordenanzas antes mencionadas traían consigo un propósito de diferenciación o segregación racial, de tal manera que, a través de las actividades que cada individuo desarrollaba en la economía, se establece un correlato en la estructura urbana y los usos del suelo; los palacios y otros tipos de arquitectura simbólica o tendiente a lo suntuoso, tenían acogida en aquellas zonas de la traza que eran más regulares o perfectamente ortogonales; para después propiciar otras zonas de una traza que podía ser irregular y construcciones de menor altura y escala, para la población indígena. Y más allá de los anillos que formaban tanto las clases privilegiadas del centro, como las de los indígenas a su alrededor, se podían encontrar las áreas de vivienda de las castas y, junto a estas, las tierras productivas o de labor.

Al desentrañar la estructura económica del virreinato, puede decirse que la ciudad viene a ser una unidad de concentración de riqueza y poder, sin embargo dependiente o subordinada de la capital colonial, aunque con autonomía e independencia en la toma de decisiones de sus asuntos urbanos, Para aquella época, la ciudad así fundada se entendió como una unidad económica, políticamente subordinada a la capital del virreinato, pero con administración libre en asuntos urbanos a partir de las decisiones tomadas por el cabildo, integrado por el las personas con mayor conocimiento, poder e ilustración, semejante a lo que hoy en día se denomina un consejo consultivo (Veracruz, Coatzacoalcos y Pánuco en primera instancia, y posteriormente Córdoba, Orizaba o Perote, por ejemplo).

c) Asentamientos que habían sido fundados por alguna de las órdenes religiosas mendicantes. Aquí los frailes designaron o comisionaron a otros compañeros, denominados visitadores, con la intención de que dieran origen a nuevos centros de población, o bien propiciaran la progresiva consolidación de aquellos que, de origen indígena, parecían estratégicos a la evangelización y la ampliación de fronteras.

Cuando se trata de poblados incluso no tan grandes, el asunto de la concentración demográfica, si bien no irrelevante, no era lo fundamental. Cuando algunos de estos poblados llegaban a ser más grandes que algunas ciudades que habían sido fundadas por real decreto, mantenían su categoría de pueblo, preservando la agrupación original de los frailes (algunos con una marcada irregularidad geométrica en su trazado como Xalapa, u otros con una geometría regular como Ixhuacán de los Reyes, Xico o Coatepec). 
Se dice que, en gran proporción, aquellos poblados que fueron fundados por los mendicantes podían también transformarse, con el tiempo, en reductos de poder o cotos con una idiosincrasia absolutista en lo tocante a los dogmas de la religión; con una paradoja: aunque se pregonaba la igualdad entre las personas, lo cierto es que se dio una discriminación para aquellos que no seguían los preceptos espirituales. En términos urbanísticos, esto es muy visible, pues en los casos en los que se utilizó un trazo de damero, aquellos por pobladores o seguidores más cercanos a la doctrina, por lo menos en los primeros años de la conquista, se ubicaban en el centro. Centralidad que, más tarde, sería ocupada por los encomenderos que lograron el mayor poder económico y riquezas.

\section{Urbanismo franciscano}

Don Gerónimo de Mendieta fue un fraile franciscano que en 1554 habría de trasladarse al territorio mexicano al recibir un encargo por parte de la Corona de España para reforzar el proceso de la evangelización de los indios. Su preocupación fue desde entonces persistente a favor de brindar protección a los naturales y, para ello, desarrolla una estrategia política y urbana. Tocante a lo político, habrá de recomendar la separación de la república de los indios de la Nueva España, no para segregarlos, buscando más bien que se respetaran sus instituciones y sus formas de gobernarse previas a la llegada de los españoles (Martí, 2008).

En cuanto a la estrategia de lo urbano, establece un modelo a manera de la sobreposición de una estructura religiosa que coexiste con los trazados indígenas y con su modo de ocupación territorial y su organización social. Formulado desde el año de 1589, es posible que haya influido, desde entonces, en aquellas poblaciones y fundaciones en las que llegaron los franciscanos. Tales ordenamientos resultan en un conjunto funcional de instituciones indígenas e hispánicas. Respecto a aquellas provenientes de la cultura indígena se adopta el calpulli o, como lo traduce de Zorita, será el barrio, organizado en centenas y veintenas y con sus respectivos jefes, los macuiltecpanpixque y los centecpanpixque.

Mientras que, procedente de la cultura española, se siguió operando con el cabildo o consejo municipal. En base a ello, conjuntamente el alcalde mayor y el guardián del monasterio, se dan a la labor de elegir el emplazamiento para fundar el pueblo. Respetando que en el centro quedaría la iglesia principal y una sede de gobierno habilitada con una plaza de armas. Para ello, los aborígenes se distribuirían en barrios proporcionalmente iguales (Nettel, 1989).

Dado que se ubicarían en una etapa en la que el humanismo había logrado influir en la Nueva España, las ideas de Mendieta lograron arraigo. A ello contribuyó que, ante la drástica disminución de la población indígena por sobreexplotación o pestes, se llegara a la noción, necesaria, de un tipo de asentamiento que permitiera, tanto a españoles como a los indios, convivir pacíficamente y, con ello, contribuir de una manera más sólida a la economía del virreinato.

Las manzanas o subdivisiones sirven para reunir a aquellos pobladores indígenas que habitaban dispersos en las proximidades del centro de la población, hasta llegar a cuatrocientas familias, lo cual de ninguna manera se consideraba un límite, ya que como se ha visto, la nueva disposición urbanística tendía a un tamaño ilimitado, si se piensa en que no había murallas, emulando aquella libertad que en su traza mostraba la Ciudad de México (Martí, 2008).

Puede entonces concluirse que es factible hablar de un movimiento franciscano de urbanización que, al ocupar los poblados indígenas pacíficamente, se realizan operaciones acaso ingenuas o incipientes, de la particularización o división del espacio urbano en un número determinado de barrios, casi siempre cuatro, con advocaciones a algún templo o iglesia.

\section{El camino real al altiplano central y sus tres rutas}

$\mathrm{Al}$ analizar la geografía del Oriente de México, puede verse que las fundaciones franciscanas se van dando de manera principal en la Provincia que entonces se denominó del Santo Evangelio, la cual ocupaba parte del territorio de lo que hoy en día es el Estado de Veracruz. Particularmente en esta geografía dichos asentamientos se agrupan en torno a una ruta extensamente conocida, a lo largo de caminos que confluían a los tres caminos o rutas principales que comunicaban al puerto de Veracruz con la Ciudad de México: una pasando por Ixhuacán de los Reyes; otra por Xalapa y Perote; y una más por Orizaba; con una ostensible jerarquía y hegemonía de la segunda, dada la incidencia de las Ferias de la Colonia. 


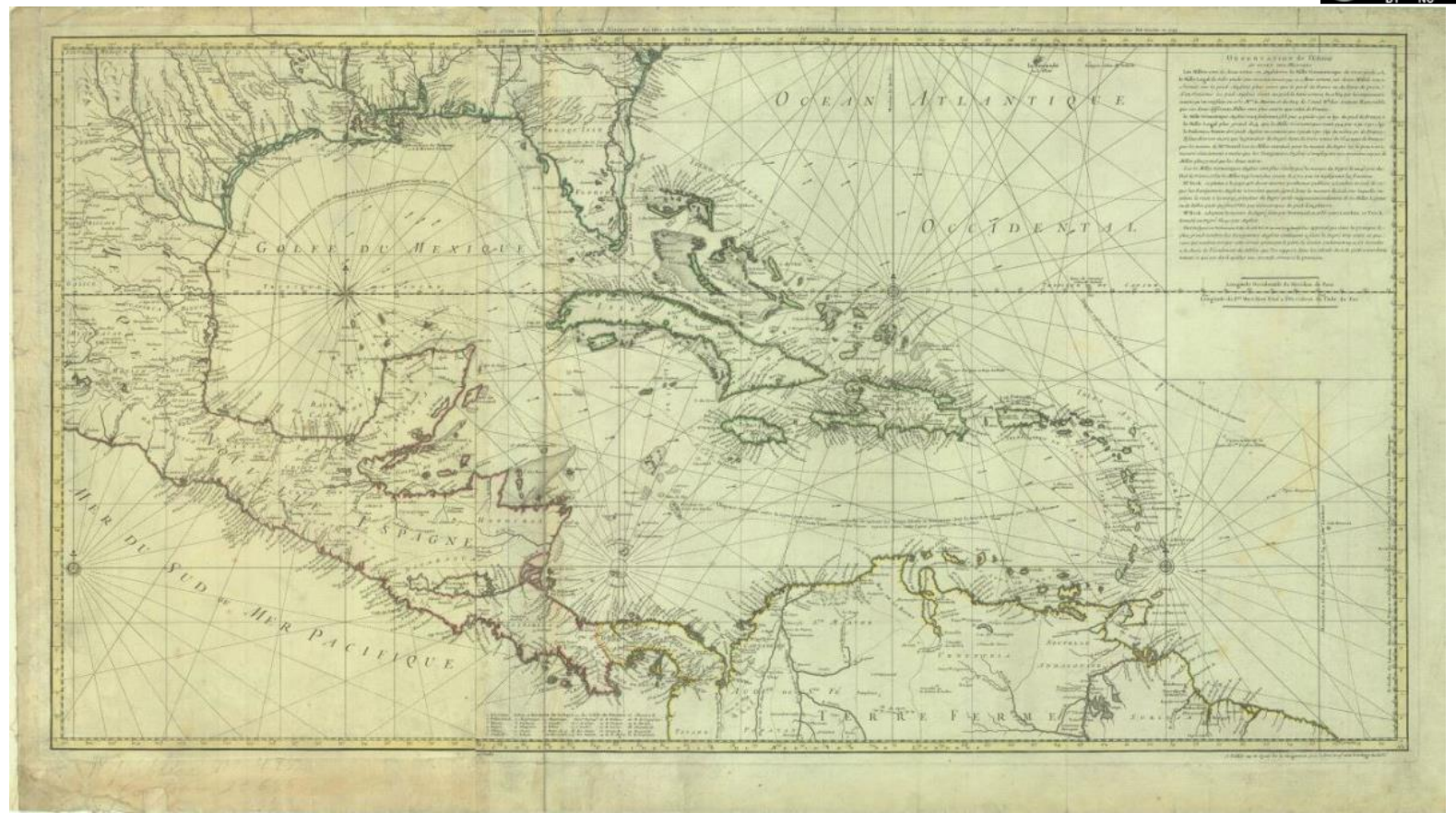

Figura 1. Golfo de México Mapa Antiguo (1740). Fuente: Mapoteca Orozco y Berra. Código clasificador: CGF.RM.M27.V11.0701. Disponible en: https://mapoteca.siap.gob.mx/index.php/cgf-rm-m27-v11-0701/

Religiosos franciscanos que formaban parte del gobierno eclesiástico del Obispado de Tlaxcala, fueron formando los establecimientos en la región del oriente del virreinato. A pesar de esta dependencia, su relativa distancia geográfica dio a las misiones de Veracruz la posibilidad de actuar en la con práctica con autonomía.

En Xalapa se estableció la fundación monacal que sería la más importante en esta área. De tal manera que teniendo como origen y destino el puerto de Veracruz, a partir de su estratégica localización en el trayecto del camino a la Ciudad de México, ofrecieron servicios. Pero también, y desde el punto de vista urbanístico, a partir de Xalapa se desarrollaron las distintas visitas y recorridos de los frailes que habrían de ir organizando los asentamientos que dependieron de dicha sede, con carácter de evangelizadora.

\section{El Puerto de Veracruz en los orígenes del urbanismo novohispano}

Comentan Pérez E. y Castillo F. (2009, 111-112) que:

Las expediciones españolas de Francisco Hernández de Córdoba en 1517 y de Juan de Grijalva en 1518 llevan a oídos del gobernador de Cuba, don Diego de Velázquez, las primeras noticias acerca de las tierras continentales; ciudades de plata, templos y estatuas de oro, ropajes y fauna exóticos, y más rumores y fantasías estimulan la curiosidad de los españoles. En ese ambiente destaca la figura de Hernán Cortés, quien, desplazándose con astucia, se alza como comandante de una armada primero exploradora, después rebelde y punitiva cuando constata aquella magnificencia, ya proverbial.

Su expedición parte de Cuba el 18 de febrero de 1519 y, tocando la peninsula de Yucatán, recorre en sucesivos cabotajes con dirección norte la costa del seno mexicano; el 21 de abril de 1519, Jueves Santo, la flota desembarca en la costa de Chalchibuecan. Es abí donde Cortés funda la Villa Rica de la Veracruv, obedeciendo más a una maniobra politica que a una intención de poblar, pues de inmediato constituye el ayuntamiento con el propósito de sustituir la autoridad del gobernador de Cuba. Así, Cortés renuncia al cargo de capitán general conferido por don Diego de Velárquezy y investido por el nuevo cabildo como justicia mayor y capitán general.

Este primer establecimiento fue formalizado antes en lo juridico que en lo fisico, pues se bizo al modo de un campamento militar, asentado sobre arenales y médanos, con construcciones rústicas provisionales, chozas y ramadas, un altar con una cruz de madera, y la horca y la picota. Una vez cumplida su función y dado lo inhóspito de estas playas, el mes de agosto la villa es trasladada hacia un sitio descubierto durante las varias incursiones de reconocimiento territorial; se trata de un lugar estratégico cercano al asentamiento indigena de Quiabuiztlán, al que los españoles nombraron Peñón de Bernal. Abi se construye la Villa Rica con mayor formalidad, annque estuvo más poblada por naturales que por españoles, ya que la colonia itineraba en su búsqueda por mayor riqueza. 
Tras la caída de Tenochtitlan, Cortés retorna a la Villa Rica e instruye a Gonzalo de Sandoval para que explore la costa oriental de México. Como resultado de esto se procederá a la fundación de la Villa del Espíritu Santo (Coatzacoalcos) y la Villa de Santiesteban (Pánuco) en 1522.

Con el progresivo crecimiento del comercio en la incipiente etapa colonial, se desarrolla un villorrio de tablas en un sitio próximo a la desembocadura del río Tenoya denominado las Ventas de Buitrón. Esta circunstancia obliga a aproximar la Villa Rica de la Veracruz al desembarco y hacia 1525 se lleva a cabo un nuevo, tercer asentamiento, ahora en las orillas del río Huitzilapan, permaneciendo aquí hasta finales del siglo XVI (actualmente La Antigua), con una traza urbana reticular.

Este asentamiento de la Villa Rica es bajo el manto jurídico de la legislación de Indias: en la Real Cédula del 26 de junio de 1523 se dicta acerca de la traza y la disposición de las tierras y solares necesarios para la vida civil. En la historia se menciona al alarife Alonso García Bravo como el que trazó la Ciudad de México y una de las pueblas de la Villa Rica, aunque no se ha precisado cuál de ellas.

Como ciudad, la entonces Veracruz, tuvo un gran auge, pues llegó a alojar a cuatrocientos españoles y a seiscientos pobladores más, entre indígenas y negros (Pérez E. y Castillo F., 2009, 112).

Con una modalidad de construcción semejante a la manera que entonces se hacía en España, hacia el último cuarto del siglo XVI se refiere que el puerto de Veracruz contaba con una iglesia mayor, dos conventos, un hospital, casas reales donde se ubicaba la Caja Real y un edificio de cabildo con cárcel, además de las instalaciones portuarias y aduana requeridas para su función, con lo que adquiere carácter de ciudad, habiéndose establecido monasterios de franciscanos, dominicos y jesuitas.

En el ir y venir de un asentamiento del puerto que fuese seguro para el embarque y el desembarque de las mercancías, se consolida progresivamente la fortaleza de San Juan de Ulúa. Sin embargo, esta no estaba libre de los ataques de piratas, razón por la cual, en el año de 1568, se decide mudar nuevamente la ciudad al sitio que desde entonces ocupa. Se inicia entonces la fortificación del puerto en lo que corresponde al islote de San Juan de Ulúa, dado el volumen de mercancías que ya se manejaba y a la intención de evitar las incursiones de piratas.

En décadas siguientes se continuará con un sistema de fortificación y hacia 1684 se inicia la construcción de la muralla. Casi cien años después, hacia 1762 se hace un recuento de la muralla del puerto de Veracruz que consta de siete puertas, en donde en cada cambio de dirección se construyeron baluartes para arsenal, pertrechos y emplazamiento de baterías que, además del reforzamiento a San Juan de Ulúa, incluyó el de Santiago, el mejor dotado en la Nueva España.

Estos baluartes permiten articular la defensa y mejorar la muralla de mar, que inicialmente consistía en una estaca y un foso. El siglo XVIII es para Veracruzy su fortaleza uno de los periodos más importantes de su bistoria, fortaleciéndose como enclave mercantil y defensivo en la zona del Golfo. Su recinto amurallado con sus siete baluartes que miraban a tierra y sus cuatro puertas (la del Muelle que comunicaba con la costa y las otras tres que se conectaban con las rutas terrestres: la Puerta de Acuña o Puerta Nueva, con el tránsito para las ciudades de Córdoba y Orizaba; la Puerta de México, que servía para el tráfico continuo de arrieros que entraban y salian de Veracruz; y la Puerta de la Merced, próxima al convento del mismo nombre, para el acceso de la gente que habitaba en extramuros (Díaz Cházaro, 1986).

Figura 2. Vista del Puerto de Veracruz con la Fortaleza de San Juan de Ulúa en primer plano (1914). Fuente: Blog Veracruz Antiguo en WordPress.

Disponible en: https://aguapasada.wordpress.com

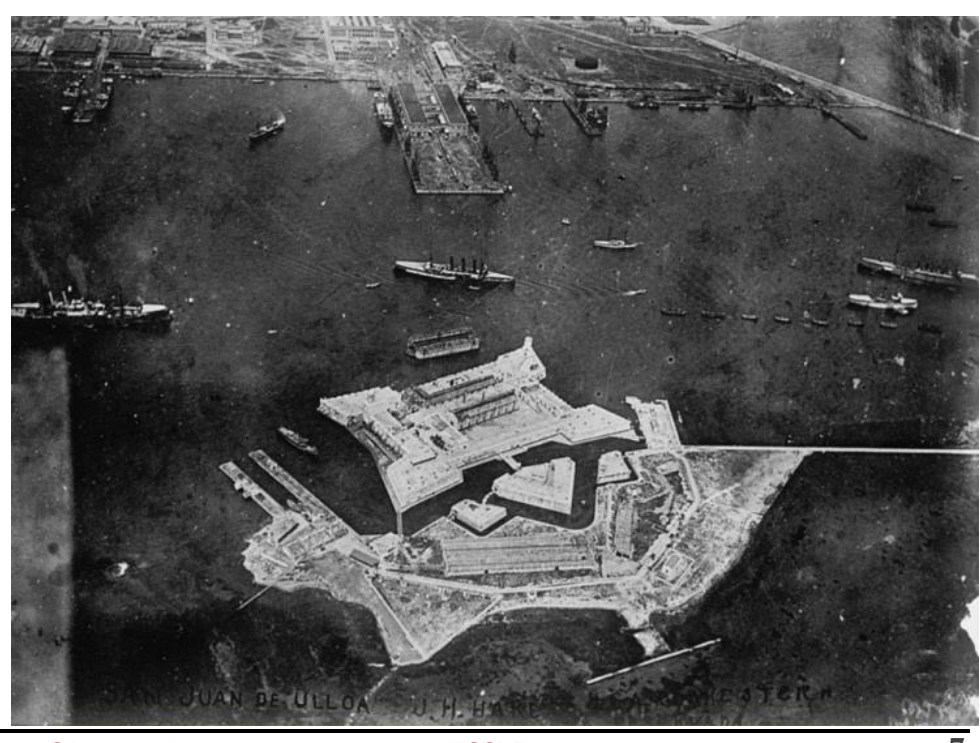


Como lo apunta Blázquez (2000, 22):

\begin{abstract}
Veracruz ya tenía un diseño urbano: la estructura de damero propuesta por el ingeniero bolandés Adrián Boot en el plano elaborado en 1615 para la construcción de la ciudad y puerto, y que se ajustó a lo marcado por las Ordenanzas de 1576 para las ciudades costeras. Las calles se cruzaban en ángulo recto formando cuadrados, lo cual dio por resultado una traza regular presidida por una plaza mayor, centro de la vida política, comercial, religiosa y social. En torno a ella se levantaron la iglesia parroquial, la Casa de Cabildos, las viviendas y sus calles principales bordeadas de portales para la comodidad de los tratantes. Detrás del edificio que alberga al ayuntamiento porteño, estaba el muelle y, en medio de una ancha playa que separaba el mar de la ciudad, la Aduana Real. Las construcciones de madera levantadas en el siglo XVII, tomando en cuenta el régimen de 1 os vientos y el clima, y de donde provino el sobrenombre de "ciudad de tablas", dieron paso a las de cal y canto, y piedra múcara para la mampostería, ladrillos, pisos y escaleras, cubierta con un enlucido de cal que ocultaba su aspereza y brindaba protección contra la acción del salitre y los vientos.
\end{abstract}

Dada su situación geográfica estratégica, Veracruz es el enclave de tránsito y comunicación del virreinato de la Nueva España con su metrópoli, teniendo como punto intermedio La Habana. Es a través del puerto de Veracruz que se da la entrada y salida de mercancías que son transportadas por el sistema de flotas desde Europa y con enlace terrestre con el interior hacia la ciudad de México, o incluso con el Pacífico, para conformar así un intercambio comercial entre el territorio novohispano que llegará hacia el oeste hasta las Filipinas y otras regiones de Asia, y hacia el este, España.

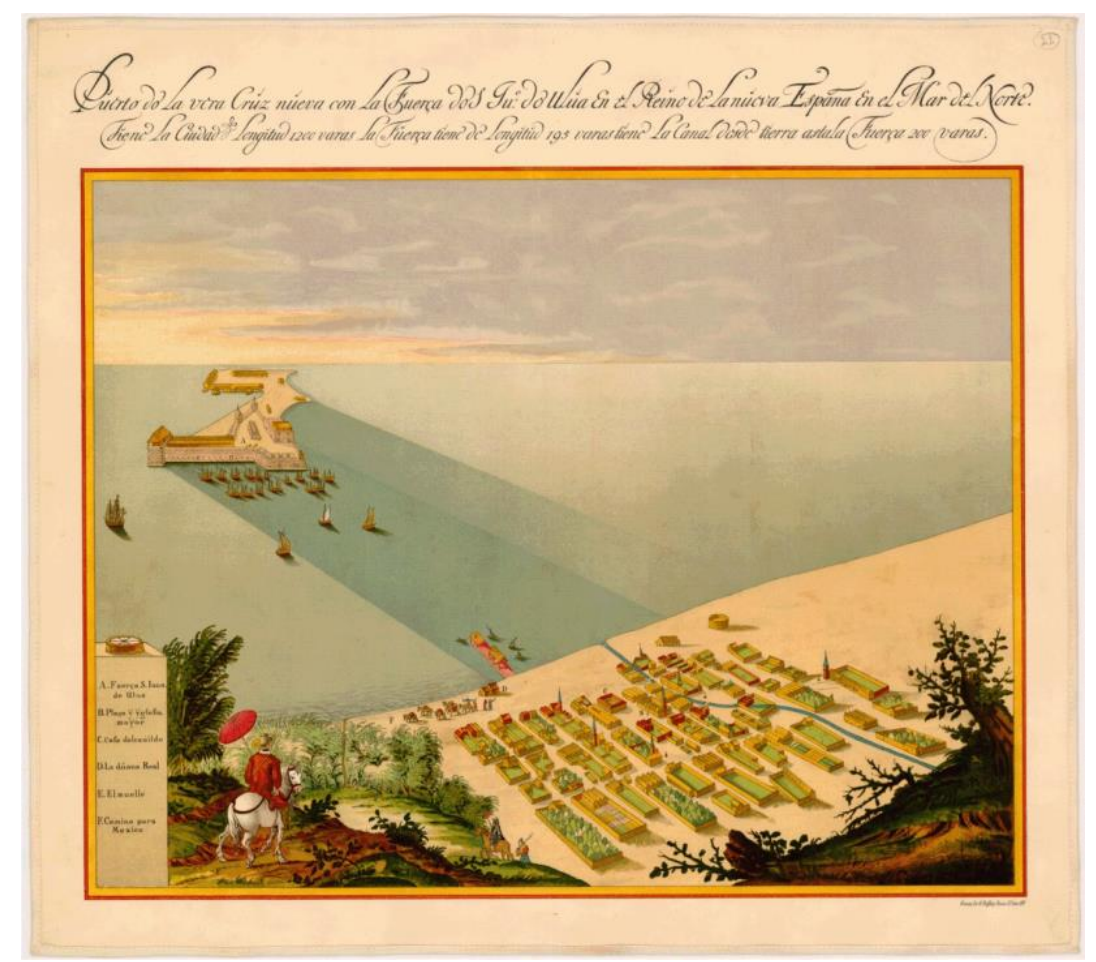

Figura 3. Vista del Puerto de Veracruz con la Fortaleza de San Juan de Ulúa en primer plano (1914). Fuente: Blog Veracruz Antiguo en WordPress. Disponible en: https://aguapasada.wordpress.com

La estructura urbanística de la ciudad queda formada por una plaza mayor, que tendrá como función principal ser el centro de la vida comercial y social, y por otras plazas de dimensiones menores a ésta, vinculadas al mercado. Una segunda zona de importancia comercial será la calle de la playa cercana a la muralla de mar, en la que se localiza el comercio cercano al muelle, la Aduana Real y su plaza (actualmente Plaza de la República).

Así, la estructura urbana está caracterizada por una retícula de calles con orientación norte-sur y este-oeste la que, en función a las ordenanzas para las ciudades costeras fortificadas, se interrumpe por una franja perimetral próxima a la zona de muralla. Las edificaciones son de uno o dos niveles, formando con ello una trama compacta, con un perfil homogéneo que sólo se ve alterado por algunas construcciones más altas como las torres y cúpulas de las iglesias. En lo que refiere a otros usos, era una práctica común que los comerciantes de más recursos destinasen las plantas bajas y entresuelos de sus establecimientos y viviendas para despachos, comercios, bodegas o caballerizas, ubicando en plantas altas la vida doméstica. 


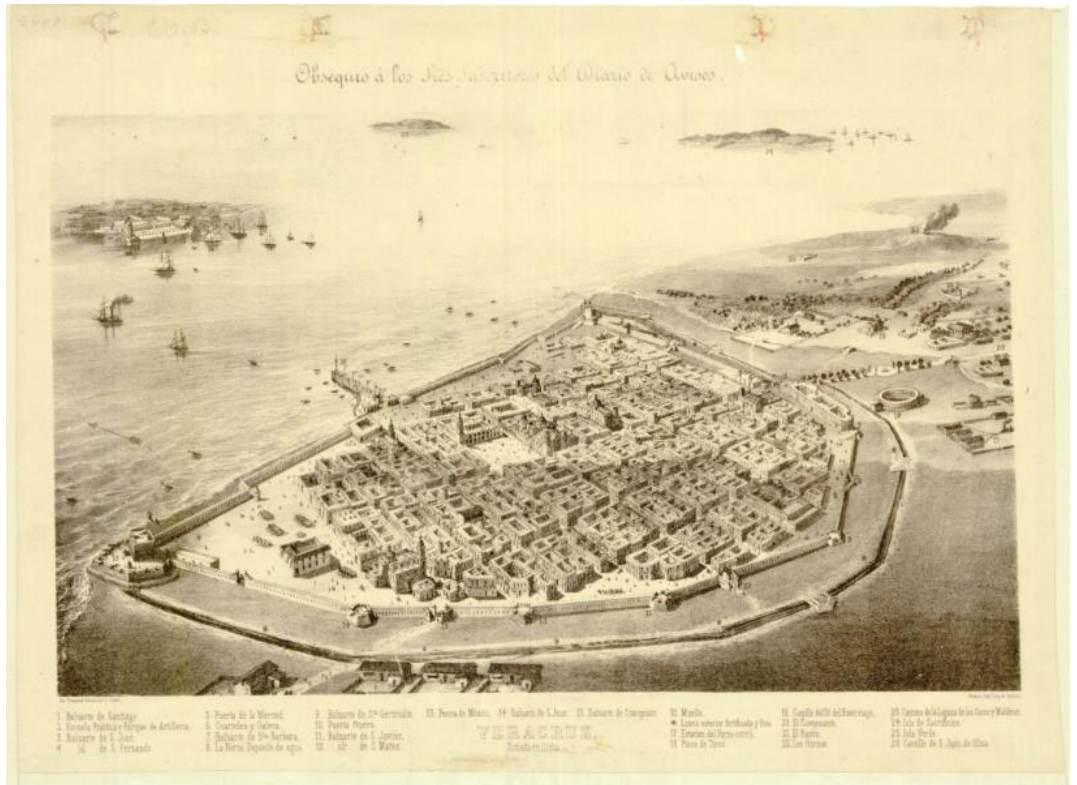

Figura 4. Vista en globo del Puerto de Veracruz. (Siglo XIX). Fuente: Mapoteca Orozco y Berra. Código clasificador: CHIS.EXP.M12.V6.0109. Disponible en: https://mapoteca.siap.gob.mx/index.php/chis-exp-m12-v6-0109/

Cierta condición marginal se reconoce en aquellos asentamientos de extramuros y construcciones cercanas a la Puerta de la Merced (como la iglesia del Santo Cristo del Buen Viaje, junto a la que se ubicaba el cementerio, el barrio de La Huaca, la iglesia de San Sebastián y el hospital de San Hipólito) o a la Puerta de Acuña o Puerta Nueva (barrio de las Californias, en donde pernoctaban las caravanas con rumbo a La Antigua y México, por el Camino Real de Xalapa-Perote-México).

\section{Coatzacoalcos (Villa del Espíritu Santo)}

La palabra Coatzacoalcos en náhuatl significa "El Escondite de la Culebra" y está relacionada a la leyenda Quetzalcóatl. Desde sus orígenes en la época prehispánica, el asentamiento fue de interés estratégico por su situación geográfica. Durante la conquista española, Don Diego de Ordaz exploró el Río Coatzacoalcos en busca de oro. Tiempo después, Hernán Cortés instruyó a Gonzalo de Sandoval la conquista del asentamiento y la fundación de la Villa del Espíritu Santo en 1522. Durante los siglos XVI y XVII, la villa fue cabecera municipal, pero por falta de hombres y por las duras enfermedades se trasladaría a la alcaldía a Acayucan.

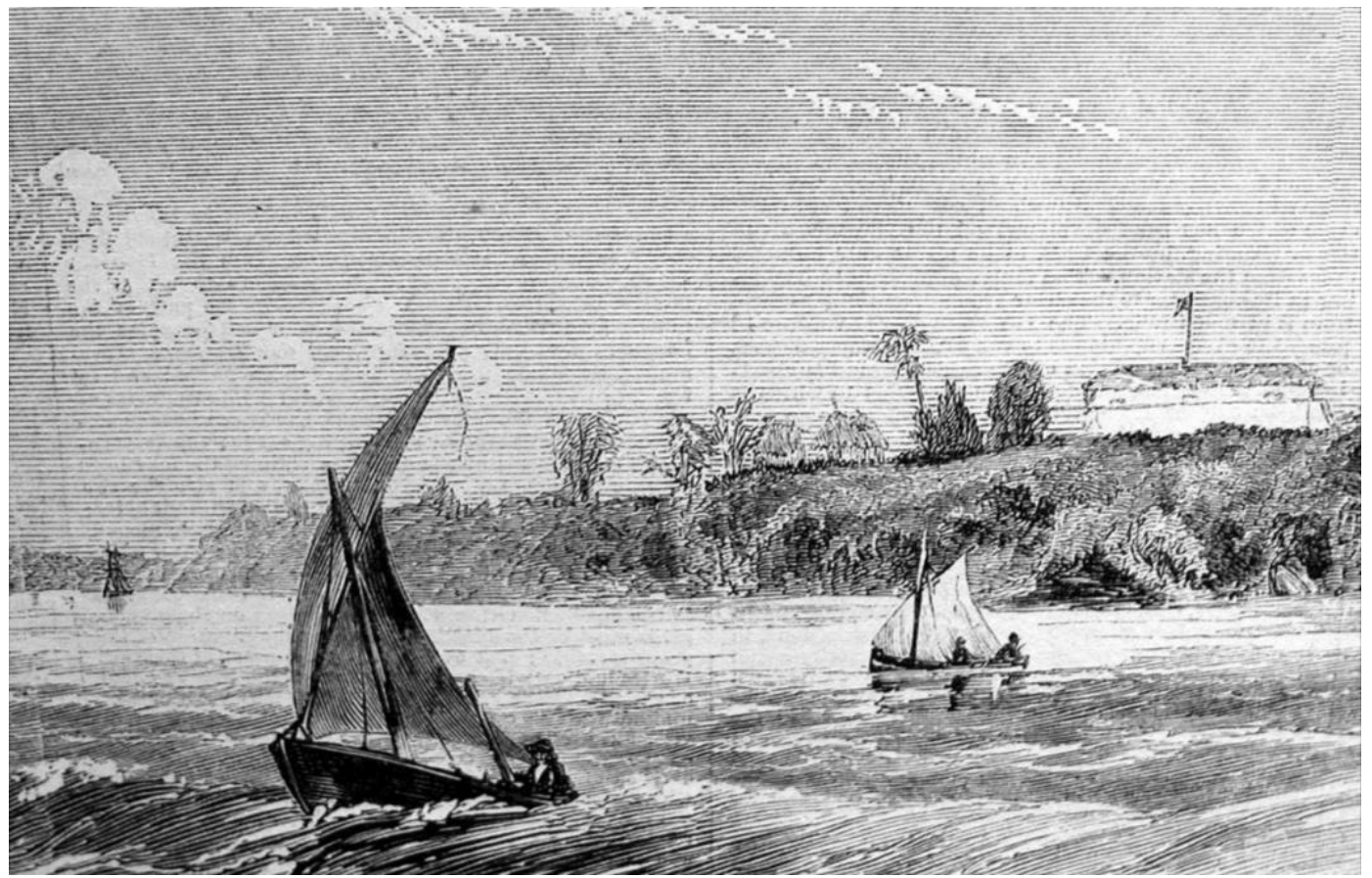

Figura 5. Falúa navegando en el río Coatzacoalcos. Grabado de la desembocadura del río Coatzacoalcos a mediados del siglo XIX. Publicado el 15 de enero de 1859 en la revista estadounidense Harper's Weekly. Fuente: Blog Veracruz Antiguo en WordPress. Disponible en: https://aguapasada.wordpress.com/2012/12/14/desembocadura-del-rio-coatzacoalcos-en-1859/ 
La Villa del Espíritu Santo sufrió constantes agresiones de piratas y la incidencia de fenómenos naturales, que muchas veces hicieron que los pobladores cambiaran de emplazamiento temporalmente en busca de una mejor ubicación para su resguardo. Durante la Guerra de Independencia (1810-1821) la región tuvo un papel importante que progresivamente iría consolidando su jerarquía como punto de paso en las líneas de comunicación entre el centro y sureste de México, hasta finales del siglo XIX en el que se inicia el desarrollo de algunas regiones del país, asociado al cultivo y a la extracción de materias primas para exportación.

\section{La Fundación de Xalapa y las Ferias del Virreinato}

Símbolo esencial en la mitología de los pueblos prehispánicos de la región a partir de su fundación que se sitúa hacia el año 1313, Xallapan fue considerada una de las moradas más importantes de los dioses en la Tierra, siendo un sitio sagrado regido por Macuilxóchitl "el señor de las flores", cuya diversidad de plantas y flores "hacía una feliz estancia a las deidades" (Espejo et al, 35-36). Aunque se ha considerado que Xalapa fue fundada por grupos de habla totonaca, hallazgos en diversos puntos de la ciudad señalan la existencia de restos de construcciones que pertenecieron a pobladores de origen olmeca. Los toltecas dieron el nombre de Xala-a-pan al asentamiento, que significa "agua en el arenal", ya qu4e debido a las características del suelo, en diferentes puntos de los barrios originarios existen manantiales.

Diversas fuentes históricas (Ramírez, 1979; Blázquez, 1992; Juárez, 1995; Winfield C., 1997) coinciden en el hecho de que el asentamiento tuvo un carácter relevante en la época prehispánica y más tarde durante el virreinato como consecuencia de hallarse en la confluencia de las rutas comerciales y de comunicación entre el Altiplano central y el Golfo de México. Durante las etapas de hegemonía de los reinos tlaxcalteca y mexica de los siglo XIV al XVI, esta importante ruta cruzaba desde la parte sureste del asentamiento que en la actualidad podemos identificar como la entrada a la ciudad de Xalapa proviniendo de Veracruz (Avenida 20 de Noviembre), siguiendo hasta el lugar que actualmente ocupa la Iglesia de La Piedad y continuando hacia el centro urbano (hoy calles Xalapeños Ilustres y Enríquez) para enlazar con el Camino a Xicochimalco (actualmente calle Úrsulo Galván) rumbo a Xico, población fundada por los frailes mendicantes.

Los cuatro núcleos indígenas o barrios integrantes de Xallapan dependieron del señorío de Cempoala y posteriormente de Tenochtitlan hasta la llegada de los españoles. Los barrios se encontraban comunicados entre sí y con los poblados de los alrededores por numerosos caminos o veredas, contando con una población ocupada principalmente en tareas agrícolas, artesanales y comerciales. El centro de la vida comercial estuvo constituido por el barrio de Xallitic donde existió un espacio abierto destinado al intercambio de mercancías o tianguis, así como temascales o baños de vapor para visitantes y gentes del pueblo.

Los españoles llegaron a las tierras que ocupaban lo que actualmente conocemos como la Ciudad de Xalapa en el año de 1519, provenientes de la costa del Golfo de México en donde ya se había fundado el primer ayuntamiento al que se designó como la Villa Rica de la Verdadera Cruz, en su camino hacia la ciudad capital Tenochtitlan en el centro del país. La población encontrada por los españoles en Xallapan se localizaba en las faldas del Cerro Macuiltépetl, a una distancia aproximada de media legua desde el camino entre la costa del Golfo de México y el Altiplano Central, ruta que no pasaba directamente por el poblado. El asentamiento estaba configurado por cuatro barrios (siguiendo la costumbre mexica) designados con los nombres de Techacapa (hacia el Sureste), Xallitic (en la parte central), Tecuanapan (hacia la parte Oeste) y Tlalmecapan (hacia el Suroeste). Cada uno de estos barrios contaba con un manantial para surtir a sus pobladores.

Debido a los inconvenientes topográficos de la primera ruta proveniente del Golfo que pasaba por Ixhuatlán-Xicochimalco rumbo a la Ciudad de México, Xalapa se convierte en punto obligado de tránsito para llegar al centro de la Nueva España. En 1526 Fray Julián de Garcés, primer obispo de la Nueva España pernocta en la ciudad. En los años posteriores, el constante flujo de viajeros da inicio a la construcción de posadas y mesones para comerciantes, arrieros y sus recuas.

En el área cercana al centro urbano donde actualmente se encuentra el Mercado Jáuregui y que durante el periodo colonial había sido un tianguis, los peninsulares establecieron el mercado principal al que llamaron la Plaza del Rey. Su estratégica ubicación haría que más tarde numerosos comercios, bodegas, posadas y comederos se asentaran a su alrededor. Fue este cuadrángulo adyacente a la llamada calle de La Amargura (hoy Revolución) el sitio donde se llevaron a cabo las ferias entre los años 1720 y 1788. Ramírez (1979, p. 5-6) apunta que: 
Establecida esa plaza como un cuadrilátero cubierto de pasto, en lugar más accesible y sobre la barranca del manantial, surgió una nueva calle-camino, boy Avenida Revolución, que unía el camino de Tlacolulan (Cruz de la Misión) con el manantial y barrio de Tecuanapan (Barragán-Zaragoza-Parque Juárez), formándose un sistema angular en forma de L, que se continuó por la actual Av. Úrsulo Galván, la salida para Xicocbimalco, resultando entonces un conjunto vial en forma de T invertida (Ramírez, 1979).

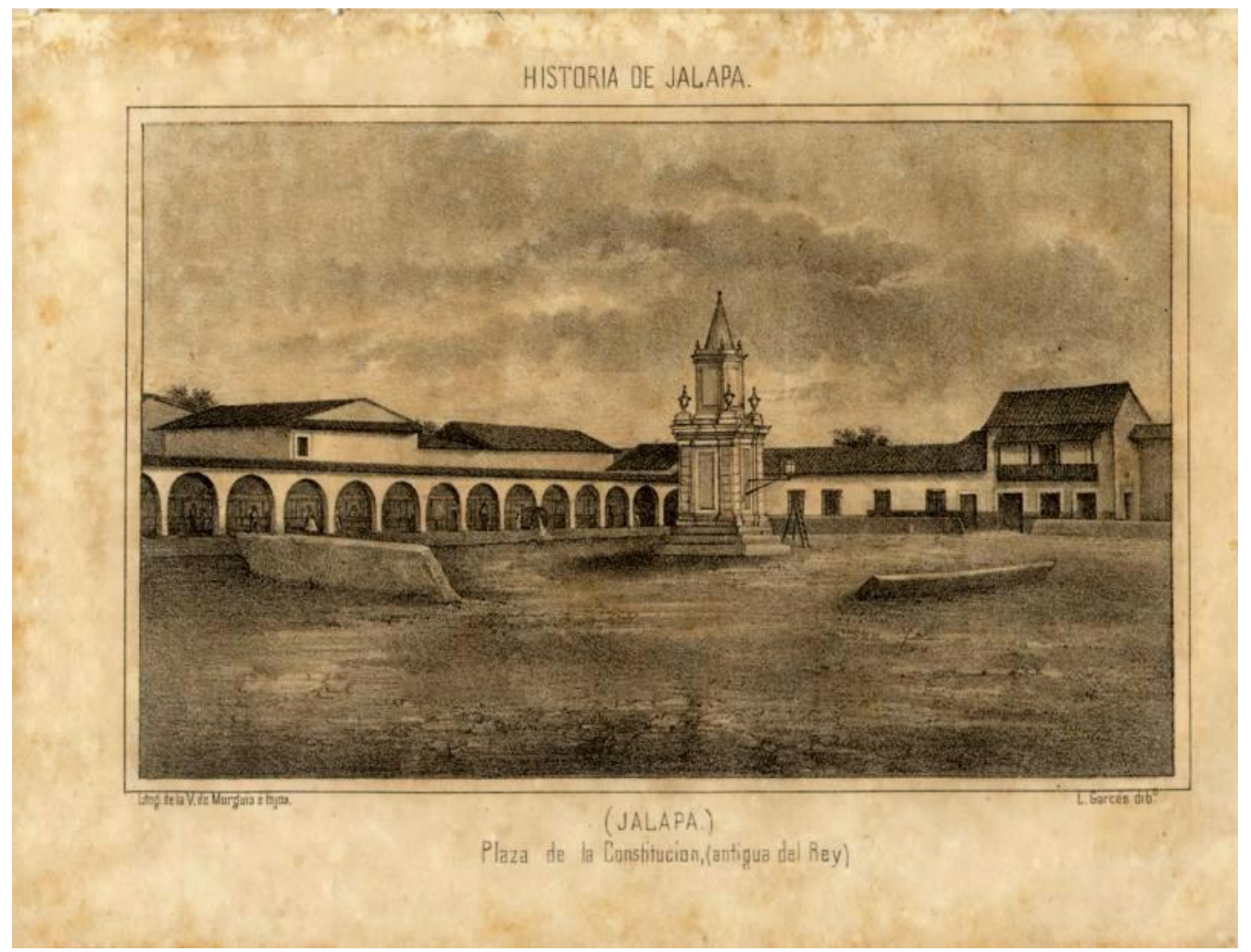

Figura 6. La Antigua Plaza del Rey en Xalapa, donde se realizaron Las Ferias del Virreinato. Fuente: Rivera Cambas, Manuel. Historia antigua y moderna de Jalapa y de las Revoluciones del Estado de Veracruz: México: Imprenta de I. Cumplido, 1869. Disponible en: https://cdigital.uv.mx/handle/123456789/47743

Parte esencial del proyecto de colonización y catequización de los naturales de estas tierras fue la construcción de edificios religiosos. Así, a partir de 1531 se inician los trabajos del monasterio y fortaleza de San Francisco concluyéndose las obras tres años más tarde; como parte del conjunto urbano de la fundación se agregó hacia el oriente el edificio del Hospital de la Inmaculada Concepción, en lo que hoy ocupa parte del Palacio de Gobierno del Estado. A lo largo del periodo colonial este sitio será morada de la orden franciscana y lugar de hospedaje para viajeros y religiosos en tránsito; los monjes ejercerían su jurisdicción hasta el año de 1641. Al igual que la gran mayoría de los monasterios fundados en la primera etapa colonial, el de San Francisco tenía la apariencia de una fortaleza, cumpliendo la función de servir como defensa en caso de insurrección de la población indígena.

En 1544 concluye la construcción de la iglesia de San José sobre una importante elevación que dominaba el barrio del mismo nombre. En 1564 se erige la ermita de El Calvario, a un costado de la ruta que partía del centro del poblado en dirección al Norte (camino a Tlacolulan), que posteriormente se convertiría en iglesia tras su reconstrucción en los años de 1805 y 1826. Es evidente el carácter de dominación simbólica que estas sucesivas construcciones religiosas llegaron a tener con el objeto de reafirmar la organización del territorio urbano a partir de las disposiciones de la autoridad franciscana.

La traza del asentamiento fue caracterizada por la imposición de elementos urbanos simbólicos como templos y capillas que sirvieron como identificación territorial a los barrios. La posición de las haciendas y ventas se convirtieron por otra parte en los límites fijos y claramente establecidos para la jurisdicción del poblado. El modelo de traza llevado a cabo por los franciscanos en Xalapa, a diferencia de otras fundaciones y asentamientos, careció de un estricto ordenamiento formal. En ello tuvo un papel determinante la topografía del lugar, por lo que se adaptó lo mejor posible las veredas y vías existentes utilizadas por los indios para vincular los diferentes barrios, con la consecuente imagen de un poblado en el que las calles eran 
en ocasiones curvas y estrechas en vez de cruzarse en ángulo recto y ser amplias, con una morfología urbana más próxima a una suma de agregados espaciales en disposición de traza de plato roto.

Posteriormente a la fundación del monasterio y templo franciscanos en el centro del poblado, los cuatro barrios indígenas fueron conservados en cuanto a su disposición, modificándose sólo sus nombres en dos de ellos: el barrio de Techacapa fue llamado San José de La Laguna, al oriente; Tlalmecapan, ubicado al poniente, fue llamado Santiago; en tanto que los barrios de Xallitic y Tecuanapan, conservaron sus denominaciones prehispánicas. Al centro urbano se agregó la nominación de Barrio de San Francisco.

Una relación de las cosas del territorio y poblado de Xalapa es requerida por mandato del Rey de España en el año de 1580. En ella se consignan las potencialidades económicas y humanas, así como otros asuntos de interés, como por ejemplo la descripción de las casas construidas con paredes de piedra, lodo y techumbres de paja, en tanto que el monasterio fue construido con paredes de cal y canto, y cubiertas de madera. La tipología más común empleada para la construcción de inmuebles habitacionales consistía en edificios de hasta dos niveles de altura formando un rectángulo que encerraba un patio plantado con árboles y flores.

El Obispo de Puebla Alonso de la Mota y Escobar refiere en el año de 1609 que en Xalapa existían unos cincuenta vecinos españoles que administraban siembras de maíz o que se ganaban la vida transportando recuas. Un relato del viajero Thomas Gage de 1634 menciona la existencia de unos dos mil pobladores en Xalapa, entre españoles e indios, y que al asentamiento se le conocía como la "Xalapa de la Veracruz", comentando además que la riqueza principal de la ciudad provenía del cultivo de la caña de azúcar, las estancias para viajeros y la crianza de la cochinilla, un insecto que servía para producir tinturas para textiles (Winfield C., 1992).

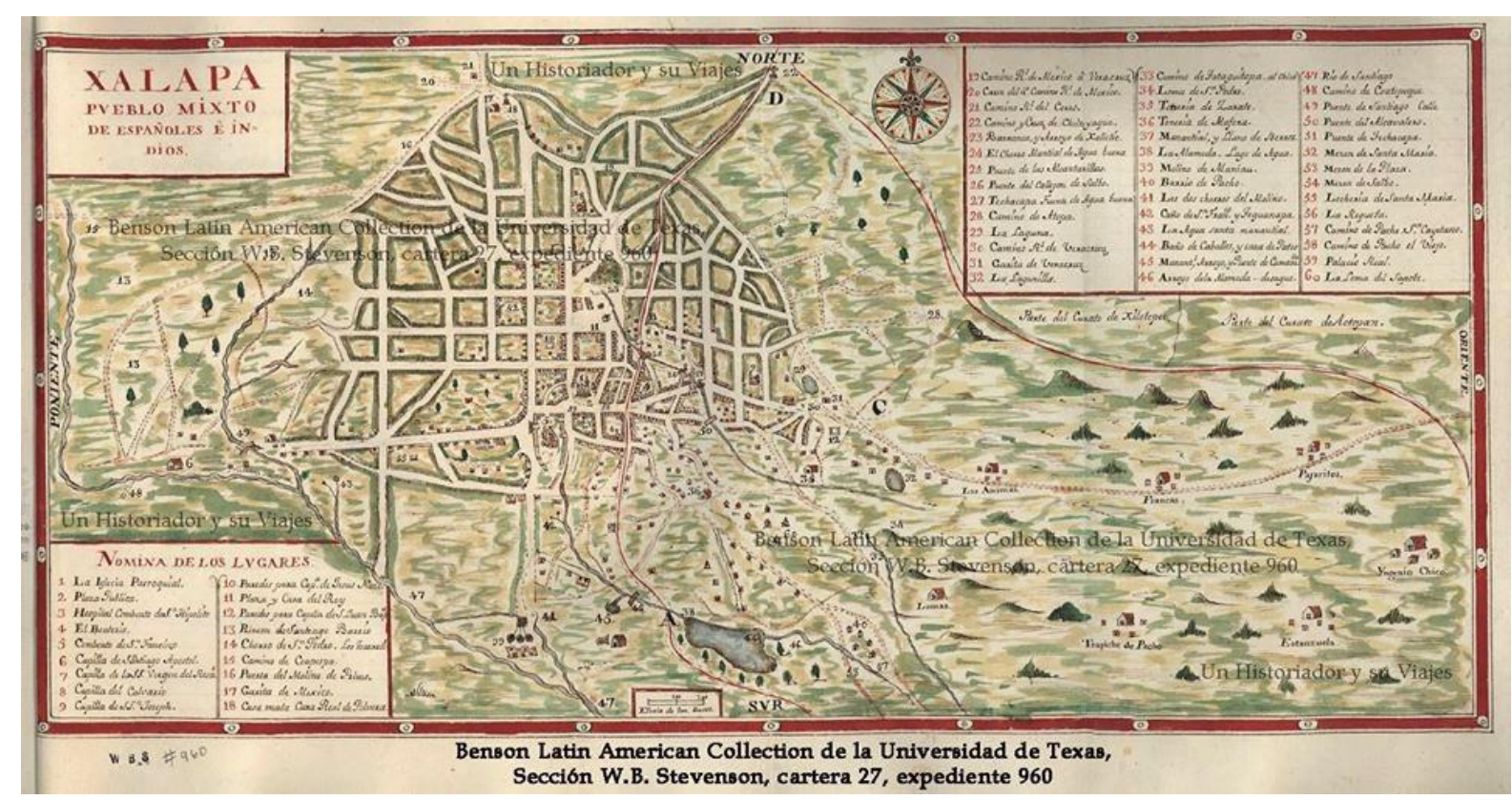

Figura 7. Mapa titulado "Xalapa pueblo mixto de españoles e indios" mediados del siglo XVIII. Fuente: Xalapa en la Historia. Disponible en: https://www.facebook.com/xalapaenlahistoria/posts/2582136751866097

La iglesia mayor o Parroquia de Xalapa inició su construcción hacia el año 1641 con aportaciones de los vecinos y se ubica a un costado de la Plaza del Rey en el centro del poblado, siendo edificada sobre un teocalli o templo prehispánico. La iglesia fue ampliada en 1722 por el sacerdote Alonso Gatica, quien además construyó tres panteones: uno para sacerdotes, otro para europeos y uno más para vascos. En el año de 1683 el pirata inglés Lorencillo saqueó Veracruz, por lo que se ordenó custodiar los tesoros con destino a España en Xalapa hasta que pudiesen ser embarcados, reforzándose algunas fortificaciones y acantonando tropas.

Los eventos que revisten la mayor trascendencia para el desarrollo de la localidad en este periodo son las llamadas Ferias de Xalapa que inician en el año 1720 y concluyen en 1788. El papel protagónico de la ciudad se debe a que, por disposición de la Corona, las mercancías provenientes de Europa y Asia desembarcadas 
en Veracruz debían ser vendidas en Xalapa. Resulta de interés destacar que el sistema colonial de comercio y tráfico de mercancías no permitía el comercio entre virreinatos y que éste se desarrollaba bajo la sanción de los monopolios comerciales de Cádiz y Sevilla. A las ferias de Xalapa concurrían comerciantes y arrieros de todo el virreinato, llegando a tener una duración de hasta tres meses. Para dar cabida a estos eventos, un gran número de casas, negocios y alojamientos fueron construidos, teniendo un papel determinante en el sentido político para que el asentamiento fuese erigido en Villa, y propiamente en ayuntamiento en 1739; y en el sentido territorial, para que las áreas de los barrios San José, El Calvario, Santiago y San Francisco ubicados en las proximidades del centro, se unificaran.

Con las modificaciones al ambiente natural y cultural de Xalapa se da otro fenómeno social: los barrios indígenas se encuentran vinculados territorialmente en un tejido urbano distinto al que ocuparon los hispanos, ya que con la llegada de los españoles se había iniciado el acaparamiento de tierras por medio de las mercedes, la encomienda y los repartimientos (Winfield C., 1997). La Hacienda de Lucas Martín fue fijada como frontera de la Villa hacia mediados del siglo XVII y años más tarde se autorizaría el establecimiento de una venta allí.

La evolución de la traza urbana de Xalapa ha respondido a etapas históricas bien definidas en las que es posible asociar crecimientos demográficos importantes o auges económicos producto de las actividades que tuvieron lugar en la ciudad. Es factible por lo tanto hablar de usos predominantes en la función de la ciudad. Así, tendríamos que de ser un asentamiento prehispánico basado en una economía de autoconsumo y en un comercio limitado, con la conquista y la posterior instauración del asentamiento franciscano así como el paso obligado de viajeros hacia la ciudad de México, Xalapa adquiere una gran importancia que habría de ser ratificada por el establecimiento de las ferias que impulsan el desarrollo económico de la ciudad, produciendo agregaciones y modificaciones a la traza pero no a sus funciones esenciales. Es por ello que la posición y función de los espacios públicos más importantes para el comercio como la Plaza del Rey (hoy Plaza Lerdo), Plaza de las Ferias (hoy Mercado Jáuregui) y atrio del Convento de San Francisco (en la actualidad Parque Juárez) ubicados en el centro del asentamiento, permanecen adaptándose a variadas modalidades de comercio.

La configuración de la traza en las áreas centrales de la ciudad respondió a dos circunstancias importantes: por una parte, la adecuación del orden urbano traído por los misioneros franciscanos a la topografía del lugar, y por otra, la utilización de los senderos y los barrios más o menos consolidados por los indígenas. A diferencia de los asentamientos y poblaciones creadas ex novo basadas en modelos ideales o utópicos, o de aquellas que respondieron a un riguroso trazado de cuadrícula sobre el terreno, la traza urbana en Xalapa durante el periodo colonial se dio a partir de una progresiva utilización de las áreas existentes entre las rutas o calles que comunicaban los distintos barrios hasta dar una cierta continuidad espacial al asentamiento, limitando con claridad lo urbano de las áreas para cultivos.

\section{Ixhuacán de los Reyes}

Teo-Iz̧̧ua-Can, o "lugar de las divinas hojas", fue el nombre que se le otorgó inicialmente al ahora municipio de Ixhuacán De Los Reyes, posiblemente en alusión al maíz (Ramírez Lavoignet, 1984, 12). Dicha denominación fue cambiando con el paso de tiempo: primero, a Ixhuacán de San Diego; más tarde, en referencia a la Corona Española, fue nombrado Ixhuacán de la Corona; y posteriormente, en homenaje a los Reyes Católicos, Ixhuacán de los Reyes; sin embargo, sus pobladores lo asocian a los Reyes Magos. Los nombres con los que se ha identificado este lugar son en su mayoría conocidos gracias a la tradición oral, que da testimonio de la influencia que tuvieron en el poblado los distintos periodos del poder religioso y político-virreinal.

La fundación de Teo-Izhua-Can aconteció posiblemente en el Siglo XII a causa de la civilización totonaca, ya que en su época fue un sitio de interés comercial y objeto de identificación de los teochichimecas y tlaxcaltecas. Actualmente el municipio se ubica en el mismo lugar donde se encontraba el pueblo indígena, en las inmediaciones de un camino que conecta al Altiplano Central con la Costa del Golfo de México y que fue utilizado en 1519 por Hernán Cortés para ingresar a Tenochtitlán. Más tarde, esta ruta se estableció como el primer Camino Real, pero dejó de tener relevancia cuando se adjudicaron algunas ventas en el trayecto Veracruz-Xalapa-Perote-Puebla-Ciudad de México (Martí, 2008). 


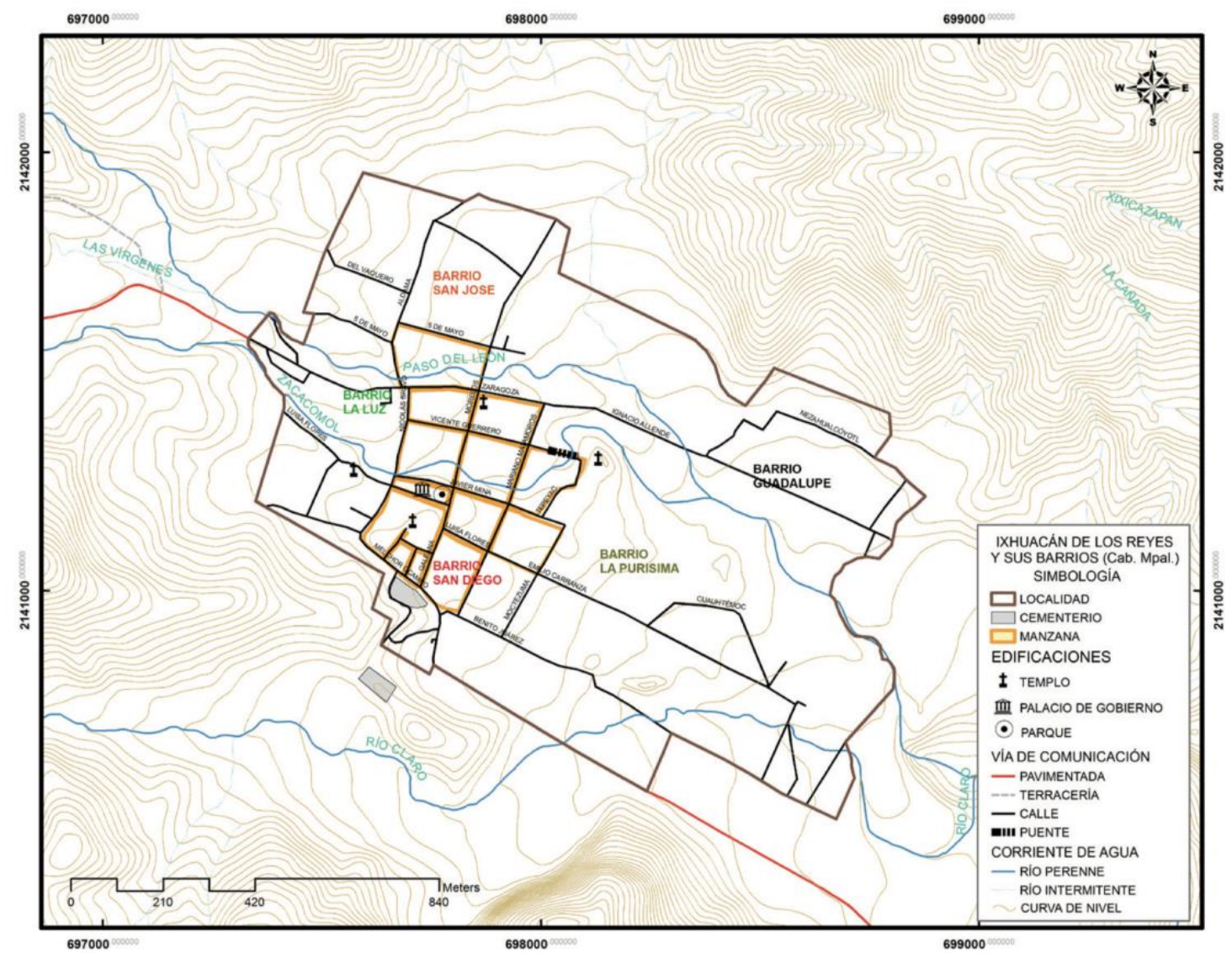

Figura 8. Plano de los antiguos barrios de Ixhuacán de los Reyes. Fuente: Martí (2016), en "Ixhuacán de los Reyes, un ejemplo del urbanismo Novo Hispano del Siglo XVI", pág. 60. Tomada del libro: Ixhuacán de los Reyes. Experiencias de Vinculación Universitaria.

Velázquez, R. A.; Uehara G.; Segura C.; coordinadores. Xalapa: Red Iberoamericana de Academias de Investigación, A.C.

Con relación a la fecha en que fue fundado el asentamiento franciscano, se han encontrado dos datos que ayudan a tener un acercamiento. Por un lado, la información que se halla en el Tercer Libro de Defunciones que comienza en el año 1600, ubicado en el Archivo Parroquial. Por lo tanto, considerando que cada libro abarca 35 años, de acuerdo con el promedio de los tres libros subsecuentes, es posible decir que dicho asentamiento data del año 1530. Por otro lado, existe información sobre la visita en 1609 de Don Alonso de la Mota, Obispo de Tlaxcala, a una población ya consolidada, donde se menciona que el obispo acudió la Sagrario del lugar. De modo que, si las edificaciones demoraban ente cuarenta y cincuenta años en finalizarse, es probable que la fecha de fundación se sitúe entre los años 1530 y 1560 (Martí, 2008).

La relevancia territorial de Ixhuacán abarcó a una amplia región en el centro y sur del Estado de Veracruz; a pesar de que existieron otros poblados política y económicamente más importantes, fue considerado como cabecera religiosa de los asentamientos vecinos, solamente después de Xalapa y Tlaxcala. Paulatinamente, hacia el siglo XVII, el asentamiento fue perdiendo algunas de las condiciones que conformaban parte su importancia, debido a su lejanía y a las dificultades que representaba arribar al mismo. Es por ello que, a causa de su mono-funcionalidad económica y al desarrollo pausado de su dinámica demográfica, en la actualidad el poblado se encuentra casi inalterado.

En lo que respecta a la forma urbana, la traza fue concebida como la organización de los componentes que conformaban el poblado: usos de suelo; ubicación de las edificaciones civiles y religiosas; la distribución de los solares; entre otros. La traza de la ciudad es de forma ortogonal, sin embargo, posee algunas irregularidades a causa de que el proyecto se materializó careciendo de herramientas de medición. Aunque existen dos ríos que atraviesan el poblado, la cuadrícula es continua y se extiende hasta comunicarse con el lado norte del Antiguo Camino Real. Aparentemente, el trazado se ordena sobre la base de dos ejes principales: uno en dirección norte-sur, que conecta una vialidad indígena ubicada en el sur con el camino virreinal; y otro en sentido esteoeste, donde se localiza la parroquia y una capilla que remata la vialidad mencionada. Asimismo, en el trazado perpendicular se acomodan cuatro barrios que hasta la actualidad mantienen nombres religiosos, divididos por los ejes ya mencionados: San José, la Purísima, San Diego, y la Luz (Martí, 2008). 
En el plano actual de solares es notable que los más amplios se localizan precisamente en torno a una plaza ubicada en el cruce de los que probablemente fueron los ejes organizadores de lugar, al igual que en el sentido longitudinal de lo que fue el camino virreinal. Los lotes de menores dimensiones se sitúan en las cercanías de este espacio central. Fuera de esa área son visibles las divisiones de predios rústicos destinados a la agricultura, formando un valle pequeño que demuestra que, probablemente, hubo una buena economía propiciada por dicha actividad; no obstante que a las afueras de esa zona productiva existen cordilleras que rodean el poblado en tres de sus puntos cardinales, y que complican ésta y otras actividades.

La organización de los usos de suelo no ha tenido grandes cambios desde aquella época, en el centro se ubica una plaza con dimensiones menores que las de otras manzanas del poblado; el cabildo y la parroquia se localizan en dos de sus costados; y en los otros dos, arquerías que conforman la fachada de cuatro viviendas donde residieron ciudadanos españoles. Se presume que contigua a la parroquia, existió una venta considerada una de las primeras en la Nueva España. En las salidas de Ixhuacán, se encuentran tres templos, dos de ellos con dimensiones aproximadas a las de una ermita, y el otro, con una jerarquía que se encuentra entre los primeros dos y la parroquia del lugar. De acuerdo con la tradición oral, en el lado sur se hallaba un monasterio que se hundió debido a las cavidades existentes en el sitio. Cabe destacar que, de los dos ríos que atraviesan el poblado, no se aprovecha su valor escénico, ni se utilizan para ordenar los usos de suelo, puesto que fluyen en el interior de los corazones de manzana (Martí, 2008).

La volumetría del poblado se distingue, primeramente, por las edificaciones religiosas, las de mayor altura en el lugar, en unos casos, debido a la altura construida y en otros, a razón de que se aprovechó la localización de los lugares con mayor altitud. En segundo lugar, se registra la elevación del edificio del cabildo, actualmente palacio municipal. En tercer término, se encuentran las casas españolas, de las cuales se conservan un par. En el último lugar de esta jerarquía, se ubican las demás habitaciones, usualmente de un nivel de escasa altura. En cuanto a la traza urbana es importante destacar que:

Las calles principales concluyen en un remate, el que funciona como un cierre espacial, de tal forma que es evidente, aun en la actualidad, el tamaño original del asentamiento y las trazas que se le han venido agregando. El espacio interior a esta demarcación no distingue entre las distintas trazas que la ordenanza real señalaba para la fundación de ciudades, por lo que se puede considerar que es un vestigio más del modo urbano franciscano. Sobra decir que la ciudad no es amurallada (Martí, 2008).

Inicialmente, durante el dominio indígena, la actividad principal de Ixhuacán fue comercial, sin embargo, desde su fundación franciscana, en el siglo XVI, funcionó como un lugar para la evangelización y como punto de descanso de las personas que transitaban la ruta Veracruz-México. Posterior a su apogeo, se transformó en una comunidad agrícola. Cabe destacar que además de los inmuebles simbólicos, civiles y religiosos, las viviendas conformaron unidades socioeconómicas debido a que adicionalmente a las habitaciones, ahí mismo se llevaba a cabo la crianza de animales y, el secado y acopio de granos. No obstante, es considerable la diferencia entre las dimensiones de los anexos productivos de una vivienda indígena y una española, ya que, en la primera, la amplitud es notablemente menor y se encuentra regularmente en forma de tapanco, a razón de que la producción de la cosecha no era destinada a producir ganancias (Martí, 2008).

A partir de que la actividad económica comenzó a ir a menos, las viviendas antiguas fueron fraccionadas, incluyendo las indígenas, edificadas de mampostería. De este modo, el programa arquitectónico inicial fue modificado, conservándose en las secciones posteriores, los amplios patios donde se secaban y guardaban los granos. Sin embargo, se conservó la composición de las fachadas y su disposición a adyacente a la banqueta, así como los tejados inclinados; los vanos anteriormente utilizados como ventana, fueron adaptados como accesos.

\section{Perote y la Fortaleza de San Carlos}

A lo largo de los siglos XVII Y XVIII, las fortificaciones en Hispanoamérica representaron una cuestión arquitectónica que llamó la atención del razonamiento militar en Europa, principalmente en España. Las escuelas de arquitectura militar italiana, francesa y española, especialmente la Academia de Matemáticas de Barcelona, evolucionaron lentamente y tuvieron que adaptarse aceleradamente a las circunstancias especiales que significaba la ubicación geográfica, política, social y económica de la Nueva España (Zapatero, 1978). 
De tal modo, hacia el siglo XVIII, las fortificaciones españolas ubicadas en América alcanzaron características particulares que las diferenciaba de otras localizadas en Europa, aunque ambas derivaran de fundamentos similares o las hubiesen proyectado los mismos ingenieros o arquitectos.

Las influencias barrocas tardias desaparecieron para dar paso en América a un neoclasicismo que imprimió orden geométrico a la traza de los edificios militares, caracterizándolos por una desnudez artística y constructiva anticipada, cuya única justificación lo era el especial arte de la guerra que, sometido a reglas o máximas, rigió sobre la edificación de estos inmuebles, dotándolos de singularidad (Martí, 2008).

En México, se encuentran como modelos de esta arquitectura militar: el Castillo de San Juan de Ulúa en Veracruz, el Fuerte de San Diego en Acapulco y la Fortaleza de San Carlos en Perote, entre otros ejemplos; todos creados en función del resguardo de las ciudades y sujetos a rigurosas normas de proporción clásica.

Como precedente para determinar la localización la Fortaleza de San Carlos, se consideró la situación que supuso la toma de La Habana por Inglaterra en el año 1762. Por ello, Joaquín de Monserrat, Virrey de Nueva España, inquietado al considerar que la invasión avanzara hacia Veracruz, pidió ayuda a la Corona Española para planear una potencial defensa, arreglando las fortificaciones que ya existían y edificando nuevas, con la finalidad de refugiar tropas, acopiar víveres y dificultar la ocupación de ciudades como México y Puebla (Gobierno del Estado de Veracruz, 1992).

De acuerdo con su petición, arribó a Veracruz el día 13 de Agosto de ese año de 1763, con el carácter de Ingeniero Director de la Colonia, El Brigadier de Ingenieros Español Don Manuel de Santiesteban, a quien el Virrey dió desde luego la comisión de hacer un reconocimiento militar de las fortificaciones del puerto y del terreno interior a sus alrededores [...] (Sánchez, 1939, p. 13).

Don Manuel Santiestan exploró las dos rutas más transitadas que llevaban de Veracruz a la Ciudad de México, la de Orizaba y Xalapa, con la finalidad de elegir el mejor lugar para construir la fortaleza tierra adentro. Por la vía de Xalapa encontró la Villa de Perote, sitio que valoró como apropiado por el tipo de clima por ser un terreno llano y considerar el rumbo de los vientos, lo que lo convertía en un buen lugar para reservar víveres y pólvora, y utilizarse como defensa de la capital de la Nueva España (Martí, 2008).

Se debe mencionar que, el lugar se seleccionó de acuerdo con los principios clásicos (Vitruvio, 1955) y con las prácticas de guerra de la época para organizar la defensa por mar y tierra (Blanes, 1986, 226). De acuerdo con lo que se lee en la placa de bronce ubicada en el edificio y por medio de correspondencia expedida por el Virrey de Bucareli hacia Carlos III se tiene conocimiento de que:

Se comenzó este real fuerte en 20 de Octubre de 1770 reinando nuestro católico monarca el Señor Don Carlos III, siendo Virrey de esta Nueva España, el Exmo. Señor Marqués de Croix e Ingeniero Director el Brigadier Don Manuel de Santiesteban. Se concluyó en 31 de Diciembre de 1776, gobernando este reino el Exmo. Sr. B. Fr. Don Antonio María de Bucareli y Ursúa.

Respecto al edificio se puede decir que se trata de un fuerte bastionado en el que el constructor utilizó un sistema muy en boga en el Siglo XVII, caracterizado por permitir la posibilidad de batir todos y cada uno de los puntos del foso de defensa a partir de la cresta de fuegos del recinto. Adopta en planta la forma de un cuadrado regular inscrito en una figura semejante de 237.15 metros por lado, contados entres los vértices de los ángulos salientes de dos bastiones consecutivos, quedando los capiteles de los baluartes orientados según los puntos cardinales, y los fuertes a su vez, según los rumbos noreste, sureste, suroeste y noroeste (Fernández K. et al, 1995).

La edificación de la fortaleza se basó en los principios de arquitectura militar de la época: firmeza, simetría y comodidad. Dentro de las formas regulares más empleadas en el diseño destacan las triangulares, pentagonales y cuadrangulares. La figura cuadrangular se relaciona con el atributo de ser la mejor opción para fortificar un sitio en la campaña o para proteger una "Línea de Circunvalación" (Zapatero, 1978). Es por ello que La Academia de Matemáticas y Arquitectura, Civil y Militar de Madrid aconsejó emplear la traza cuadrangular que permitía cuatro formas de composición.

La escuela de fortificación española fue axiomática; distinguió entre fortificaciones regulares e irregulares, concediéndole mayor valor al diseño de las primeras. Entendió como regulares aquellas cuyas trazas, en los lados y los ángulos, eran iguales entre sí o uniformes por todas sus partes (Martí, 2008).

Por tal razón, la Fortaleza de San Carlos se adecuó a la traza cuadrangular, rematada en cada borde de sus lados oblicuos por un baluarte con aspecto de rombo truncado. Sus medidas se adaptaron de acuerdo con 
la regla que predominaba a finales de siglo XVIII, al presentar una medida de 800 pies en la línea de defensa, dato verificado en el plano de levantamiento de dicha Fortaleza elaborado por la Dirección de Obras Públicas del Gobierno del Estado de Veracruz (Martí, 2008). Aunque por orden real las dimensiones de ajustaron a los cánones de la época, se conoce que el proyecto original consideraba medidas más reducidas.

Al igual que Vitruvio (Vitruvio, 1955) compuso al proyecto de ichonografia o planta del edificio; orthographia o sección de un plano perpendicular al horizontal, y escenographia o perspectiva, para este caso el mayor énfasis en el uso de la proporción fue en la ichonographia, especificándose en los axiomas las medidas de los lados de las figuras, en concordancia estricta con la geometría y el arte de la guerra (Martí, 2008).

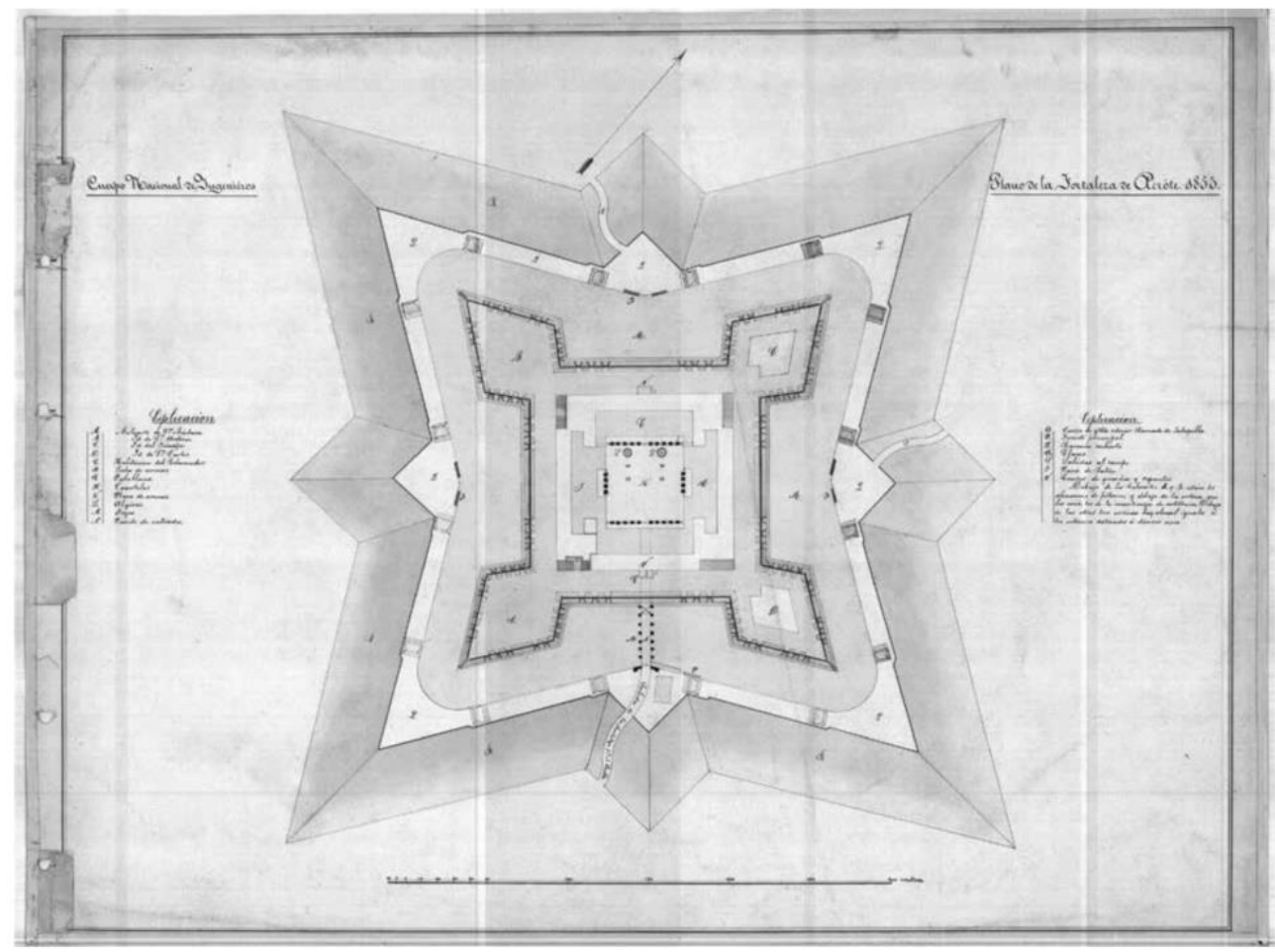

Figura 9. Plano de la Fortaleza de Perote, por el Cuerpo Nacional de Ingenieros (1855). Fuente: Mapoteca Orozco y Berra, SAGARPA. Código clasificador: 1555-cge-7261-4.

En el trazado de la fortaleza es posible observar seis perímetros. El primero, el que define el límite del glacis o talud del área que circunda la edificación. Fue proyectado sólo conociendo la longitud de la línea de defensa, en cada lado del cuadrado del diseño original caben cuatro cuadrados menores, que son atravesados en su totalidad por una diagonal que, a la par con el cuadrado girado, define el margen del glacis. El segundo perímetro, concierne a la muralla inicial cuya línea se genera como resultado del trazo geométrico del margen exterior del glacis, que se asiste con la proyección de líneas ortogonales hacia los márgenes del glacis para crear el contorno interno del mismo, completando el diseño con un cuadrado girado en el interior.

El tercer acotamiento corresponde al exterior del foso y se basa en las líneas ya presentes, donde se ubican los puntos que permiten hacer centro y trazar medias circunferencias. El trazado de la muralla del fuerte, conformada por la de los baluartes y flancos, comenzó por la delimitación de los primeros, y se auxilió del trazo interior del glacis y el cuadrado en su interior, cuyos puntos donde se unen los lados son definidos dentro de cada baluarte. Por último, la vía ubicada dentro del fuerte se conforma por un cuadrado en su interior con dimensiones que resultan ser un patrón de las otras, donde sus vértices son resultado del cruce de los trazos que dan origen a los baluartes.

Sanz (2002 y 2010) refiere que la construcción que se inicia en 1770 bajo la dirección del ingeniero Santiesteban considera dos proyectos: uno inicial, que es un fuerte común de planta cuadrada, con una plaza de armas interior y cuatro edificios para el hospedaje de la tropa, incluyendo, además, almacenes subterráneos para pólvora en dos de los baluartes, defensas exteriores de foso, camino a cubierto y glacis. El segundo proyecto obliga a Santiesteban a hacer un ajuste de dimensiones mayores. Finalmente, la Fortaleza de San Carlos cayó en abandono debido a que no se materializaron los indicios de guerra del periodo virreinal que originaron la construcción del conjunto. 


\section{Referências}

Ayuntamiento de Ixhuacán. (1996). Transcripciones de documentos sin título provenientes del Archivo General de la Nación, Ramo Indios, Tomos 6 y 24. Biblioteca Nacional de Madrid, Memoriales del Obispo de Tlaxcala. MS6877.

Blanes, M. T. (1986). Plástica del Caribe. La Habana: Letras Cubanas.

Blázquez, D. C. (1992). Xalapa. Colección Veracruг: imágenes de su historia. Xalapa: Archivo General del Estado de Veracruz.

Blázquez, D. C. (2019). Comerciantes y desarrollo urbano: la ciudady puerto de Veracruz en la segunda mitad del siglo XVIII en Tiempos de América. Número 5-6. Páginas 21 a 36. 2000. Disponible en: http://dialnet.unirioja.es/servlet/autor?codigo=365252.

Díaz, C. M. (1986). La Ciudad de Veracruz en CultuArte, Número 1. Mayo.

Fernández, K. C. et al. (1995). Fortaleza de San Carlos. Perote, Veracruz: Ensayo producido para la Maestría en Restauración Arquitectónica de Bienes Culturales. Xalapa: Universidad Veracruzana.

Gobierno del Estado de Veracruz (1992). Perote y la Fortaleza de San Carlos. Historia y Señorío. Xalapa: Editora de Gobierno.

Juárez, M. A. (1995). “Las ferias de Xalapa 1720-1778” en Las ferias de Xalapa y otros ensayos. Colección Contra Viento y Marea. Xalapa: Instituto Veracruzano de Cultura.

Kubler, G. (1984). Arquitectura Mexicana del Siglo XVI. México: Fondo de Cultura Económica.

Martí, C. D. (2019). "Ixhuacán de los Reyes, un ejemplo del urbanismo Novo Hispano del Siglo XVI” en Ixbuacán de los Reyes. Experiencias de Vinculación Universitaria. Velázquez, R. A.; Uehara G.; Segura C.; coordinadores. Xalapa: Red Iberoamericana de Academias de Investigación, A.C., 2019. Disponible en: http://redibai-myd.org/portal/wpcontent/uploads/2019/11/Libro-Ixhuacan.pdf.

Martí, C. D. (1 de agosto, 2008). Blog Arquitectónik. Xalapa. “La Fortaleza de San Carlos. Perote, Ver., Mex.”. Disponible en: https://arkitectonica.blogspot.com/2008/08/la-fortaleza-de-san-carlos.html.

Martí, C. D. (2 de agosto, 2008). Blog Urbanísticka. Xalapa. "Ixhuacán de los Reyes, un ejemplo del urbanismo Novo hispano del siglo XVT'. Disponible en: https://arkitectonica.blogspot.com/2008/08/la-fortaleza-de-san-carlos.html.

Méndez, S. E. (1988). Urbanismo y morfología de las ciudades novohispanas. México: Universidad Nacional Autónoma de México y Universidad Autónoma de Puebla.

Moro, T. (1990). Utopía. Prólogo de Manuel Alcalá. Sexta edición. Número 282 de la Colección “Sepan cuántos...”. México: Porrúa.

Nettel, P. (1989). La utopía franciscana en la Nueva España. México: Universidad Autónoma Metropolitana-Xochimilco.

Pérez, E. R. y Castillo, F. E. (2009). “Arquitectura y patrimonio histórico” en Velasco Toro, José y Félix Báez Jorge: Ensayos sobre la cultura de Veracruz: Xalapa: Universidad Veracruzana, pp. 111-126.

Ramírez, L. D. (1973). “Testimonios para una historia de Perote” en Seminario de Historia. Xalapa: Universidad Veracruzana y Ayuntamiento Constitucional de Perote.

Ramírez, L. D. (1979). "Las Calles de Xalapa” en Cuadernos educativos. Escuela de Bachilleres Vespertina y Nocturna “Artículo $3^{\circ}$ Constitucional”. Xalapa: Dirección General de Enseñanza Media del Estado de Veracruz.

Ramírez, L. D. (1984). “Ixhuacán de los Reyes” en Cronos. Revista de Difusión Cultural, n. 33. Xalapa.

Sánchez, L. M. (1939). El Castillo de San Carlos en Perote. Colección Suma Veracruzana. Serie Historiográfica. México: Editorial Citlaltépetl.

Sanz, M. S. (2002). Tres fortificaciones en Nueva España. Estudio arquitectónico-constructivo. Tesis doctoral presentada en la Escuela Técnica Superior de Arquitectura de la Universidad de Barcelona. Barcelona.

Sanz, M. S. (2010): "Fortaleza de San Carlos. Perote, Veracruz-México" en Fortalezas.org/ Fortifications. World. Disponible en: http:// fortalezas.org/?ct=fortaleza\&id_fortaleza=947.

Vitruvio, P. M. (1955). Los diez libros de Arquitectura. Traducción del latín, prólogo y notas de Agustín Blázquez. Barcelona: Iberia.

Winfield, C. F. (1992). Viajeros en Xalapa (siglos XVII al XIX). Xalapa: H. Ayuntamiento de Xalapa.

Winfield, C. F. (1997). Historia de Xalapa desde la época prehispánica hasta nuestros días. Presentación de Carlos Rodríguez 
Velasco. Xalapa: H. Ayuntamiento de Xalapa y Artes Gráficas Graphos.

Winfield, R. F. (2010). "De la forma urbana como utopía de la sociedad ideal” en F. N. Winfield Reyes (coord.) Historia, teoría y práctica del urbanismo. Xalapa: Universidad Veracruzana, pp. 65-74.

Zapatero, J. M. (1978). La fortificación abaluartada en México. Barcelona: Complejo de Artes Gráficas Medinaceli. 